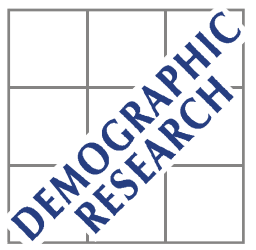

Demographic Research a free, expedited, online journal of peer-reviewed research and commentary in the population sciences published by the Max Planck Institute for Demographic Research Konrad-Zuse Str. 1, D-18057 Rostock · GERMANY www.demographic-research.org

DEMOGRAPHIC RESEARCH

SPECIAL COLLECTION 3, ARTICLE 7

PUBLISHED 17 APRIL 2004, PAGES 155-176

www.demographic-research.org/special/3/7/

DOI: 10.4054/DemRes.2004.S3.7

Research Article

\title{
Childbearing Developments in Denmark, Norway, and Sweden from the 1970s to the 1990s: A Comparison
}

\section{Gunnar Andersson}

This special collection is in honor of Jan M. Hoem on his $65^{\text {th }}$ birthday. The authors presented their papers at a working party at the Max Planck Institute for Demographic Research in Rostock, Germany in April 2004. The collection is edited by Gunnar Andersson and Gerda Neyer.

(C) 2004 Max-Planck-Gesellschaft. 


\section{Table of Contents}

1 Introduction 156

2 Population-register data 157

3 Childbearing trends in Denmark, Norway, and 159

$4 \quad$ Fertility rates by age of mother and time since 166 previous birth

$\begin{array}{lll}5 & \text { Reflections } & 170\end{array}$

6 Acknowledgments 172

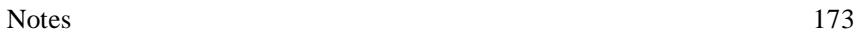

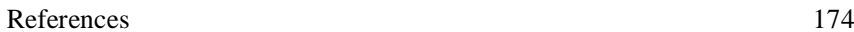




\title{
Childbearing Developments in Denmark, Norway, and Sweden from the 1970s to the 1990s: A Comparison
}

\author{
Gunnar Andersson ${ }^{1}$
}

\begin{abstract}
The purpose of this paper is to provide a comparative overview of recent trends and patterns in childbearing in the three Scandinavian countries: Denmark, Norway, and Sweden. We use indexes produced by applying event-history techniques to register data of the three countries in order to describe and contrast fertility developments by birth order over the last three decades of the $20^{\text {th }}$ century. By combining the same type of data from three countries, we get a very accurate picture of various cross-country differences in fertility levels. We can determine to what extent developments in one country are specific to that country, and to what extent they are part of a more general Nordic pattern of childbearing. We demonstrate how Swedish fertility has fluctuated relatively strongly during the whole period while Danish and Norwegian fertility have evolved more gradually. Nevertheless, trends in Norway and Sweden appear fairly synchronized. A turnaround from decreasing to increasing levels of childbearing is, for example, evident in 1977 in both Norway and Sweden. In Denmark, a similar turnaround occurs considerably later, in 1983. A shift to shorter birth intervals in Sweden during the 1980s is specific to that country and contributed to its stronger increase in fertility during that decade.
\end{abstract}

Max Planck Institute for Demographic Research, Konrad-Zuse-Straße 1, D-180 57 Rostock,

Germany. Phone: $\quad$ +49 (381) 2081 185, Fax: $\quad$ +49 (381) 2081485 ,

E-mail: andersson@demogr.mpg.de 


\section{Introduction}

The three Scandinavian countries Denmark, Norway, and Sweden have many characteristics in common. Their populations speak practically the same language, share the same culture, have organized their societies in very similar ways, and also have many demographic characteristics in common. These countries have even organized their vital statistics in a fairly similar way, a feature that we will exploit in the following presentation of fertility developments in the Scandinavian countries over the last three decades.

A very common and simple way of measuring levels and trends of fertility is to calculate period Total Fertility Rates, which is done by summing age-specific fertility rates for each year of interest. This amounts to the construction of a synthetic cohort for each year considered. Evidently, the TFR is too crude a measure of fertility to give accurate information about important features of childbearing trends: It does not give any information about whether period effects have been different for people at different stages of their family-building career. A further disadvantage is the TFR's very nature of being a synthetic-cohort construct. Despite being based on period data, it is very often interpreted in terms of cohort behavior. As such, it tends to exaggerate changes in fertility in periods when women and men are postponing or are speeding up their childbearing. Hajnal (1947) was the first to point out this feature. In recent years, it has stimulated a new stream of literature aiming at various alternative measures of fertility, with the ability to better reflect the underlying cohort behavior than what the conventional TFR can do (Rallu and Toulemon 1994, Bongaarts and Feeney 1998, Kohler and Ortega 2002a,b, Sobotka 2003). An opposition to such a strategy, as formulated by van Imhoff (2001), instead argues that the whole idea of trying to infer cohort fertility from period fertility measures is dubious.

A more suitable approach to describe fertility change over calendar time might be to apply a fertility metric that makes sense, also from a clear-cut period perspective. After all, measurements expressed as 'children per woman' are not the best ones to describe what is going on during a period (Ní Bhrolcháin 1992). In the present description of fertility change in the three Scandinavian countries, we use modern statistical methods to depict period trends in childbearing. Following an approach first suggested and described by Jan Hoem (1991,1993a), we present parity-specific indices of childbearing risks based on a modern version of indirect standardization. Such an event-history analysis allows for:

- a disaggregated description of demographic change, displaying trends in childbearing for a number of subgroups of women, 
- an efficient use of available data, controlling for compositional changes over the different demographic categories that are considered, and

- the use of a metric that is appropriate for a period-based analysis, giving information about changes in the propensity to give birth for the various groups of women.

Such an approach has already been used in order to depict childbearing trends in Sweden and Norway (Andersson 1999, 2002, Kravdal 2002a). The major contribution of the present paper is that we have been able to join the longitudinal data on childbearing of women in these two countries with similar data on childbearing in Denmark in order to get a full-fledged three-country comparison of the childbearing dynamics in Scandinavia. For Denmark, it is the first time that such an elaborated presentation of trends in childbearing has been done.

By applying our event-history techniques to the combined population-register data of three countries, we are able to get a very accurate picture of differences in trends in childbearing in the countries considered, as well as to bring out differences in fertility levels between women in the three countries. It is our hope that our description will be useful, also when trying to understand why trends have evolved similarly or differently in the different Scandinavian countries. By comparing and contrasting the fertility developments of women from very similar societies, described by the same kind of data and methods, we might in some cases be in a position to derive explanations of observed changes in fertility. Various interventions in the manner of policy changes and economic turnarounds have occurred in the three countries during our study period. When an intervention occurs in one country but not in the other two, we may be able to say something about the possible specific impact of that event on childbearing dynamics, since we can observe what happened in the absence of the same intervention when looking at the development in the two neighboring countries.

\section{Population-register data}

The data for our calculations stem from the population-register systems of Denmark, Norway, and Sweden. These systems have a long history of full and reliable coverage of the local populations and their vital events. They are characterized by a very high accuracy, a feature that has been maintained after the computerization of the systems since the end of the 1960s. Our own computations are based on the records of registered live births and the corresponding exposure times of risk for various subgroups of women. These numbers are derived from the longitudinal information on the dates of each recorded birth of all women in Norway and Sweden born in 1935 and onwards, 
and of all women in Denmark born in 1945 and later. The data set for Norway contains foreign-born women, while such women were excluded from the other two data sets (Note 1). Kravdal (2002a) performed the various aggregations of individual-level data for Norway. Andersson (2002) joined this data set with similar data for Sweden, and in the present study we add corresponding data from Denmark. For further background information on register data on childbearing in Denmark, see Knudsen (1993).

We focus on period effects in childbearing and display fertility trends in the three Scandinavian countries since 1971. The data for Denmark cover the years up to 1996, while the Norwegian data extend to 1997, and those of Sweden to 1999. We present relative risks of first, second, third, and fourth births for each year during 1971-1999 for which we have data, standardized for age of woman and time since any last previous birth of hers. In practice, our estimation techniques amount to the estimation of proportional-hazards (intensity-regression) models, which is a standard tool for the analysis of any time-dependent data (Note 2).

In summary, we present relative risks of childbearing for each parity progression separately, based on the number of births and the appropriate population under risk of giving birth to a child of the actual order. We present separate analyses of first births for childless women in their "20s" (15-29 years), and childless women in their " 30 s" (30 years and older), since trends and patterns in fertility differ very much for younger and older nulliparous women. We use the following set of variables in our analysis:

- country: Denmark, Norway, and Sweden,

- calendar year: years 1971 to 1996 (Denmark), 1997 (Norway), and 1999 (Sweden) in single calendar-year groups,

- age group of woman: ages 15-19, 20-22, 23-25, 26-29, 30-33, 34-37, and 3844.

For women who have already given birth to at least one child, we also include a variable for the duration since the previous birth, that is:

- age of youngest child: ages 0,1, 2, 3-4, 5-6, and 7-9 years, where age 1 corresponds to the year following the child's first birthday, etc.

For each birth type, we present relative risks of childbearing for the interaction between "country" and "calendar year", standardized for the age variable(s). These risks give information on period changes in childbearing in the countries considered, as well as information on various differences in fertility levels between women of the three countries. For a further discussion of our estimation techniques, see also Kravdal (2002b). Kravdal suggests that it might be more appropriate to estimate our fertility 
models simultaneously with all parity progressions included in one set of models. This would allow us to include a factor for unobserved heterogeneity into our modeling. In the case of Norway, he demonstrates that such a procedure affects period trends slightly downwards, but that the impact is not too impressive. In our presentation, we stick to the more conventional approach of basing our regressions on observable variables only.

\section{Childbearing trends in Denmark, Norway, and Sweden}

As an introduction, we present aggregate trends in childbearing in Denmark, Norway, and Sweden as they appear in period Total Fertility Rates (TFR) over the years since 1971 (Figure 1). In all three countries, fertility declined during the 1970s, just as in many other parts of Northern and Western Europe. In Denmark, the decline continued slightly longer than in the other two countries, namely until 1983, when the TFR reached an all-time low of only 1.38 children per woman. From 1984 onwards, the trends of all three countries reversed. The TFR increased more rapidly in Sweden than in the neighboring countries, but this was followed by another trend reversal in the early 1990s. By contrast, during the 1990s, the TFR of Denmark and Norway leveled off at approximately 1.8 children per woman. On average, the TFR has been the highest in Norway and the lowest in Denmark. The TFR of Sweden has fluctuated the most.

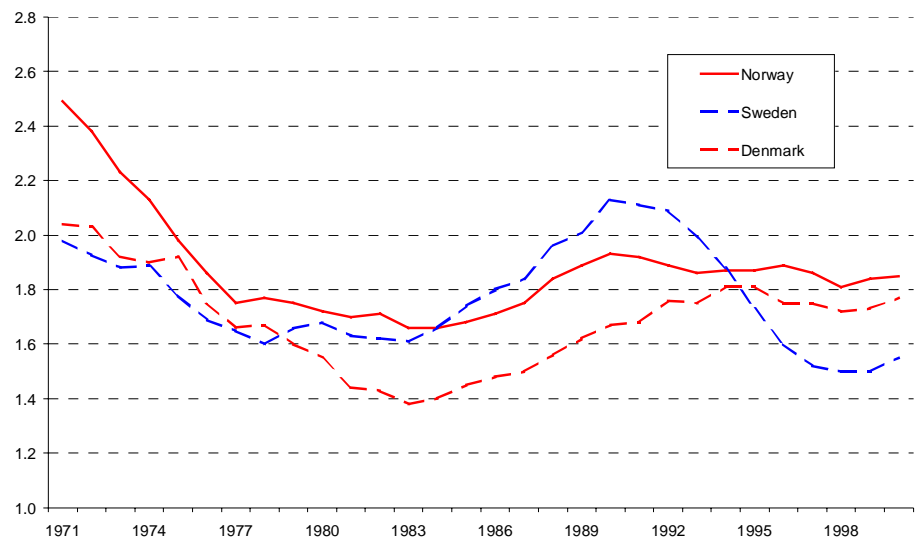

Figure 1: $\quad$ Total Fertility Rate for Denmark, Norway, and Sweden, 1971-2000. 
In Figures 2 to 6, we proceed to our own presentation of childbearing trends. We present the relative risks of childbearing by calendar year and country, with one diagram for each birth type that we cover. In each case, the risks are given relative to that of Sweden in 1977 (Note 3). Figure 2 displays relative risks of entry into motherhood for childless women aged 15-29 years. It turns out that long-term trends in first-birth rates of younger women have been fairly similar in the three countries, but that the levels of first-birth fertility differ somewhat. Norway displays the highest firstbirth fertility of young women, while Sweden has the lowest level of young first-birth fertility during most years. In all countries, first-birth rates decreased sharply during the 1970s and early 1980s. In all countries, the decline was interrupted in 1984, by increasing birth intensities in Sweden, and by stabilizing birth intensities in Denmark and Norway. The increase in Sweden was again reversed at the beginning of the 1990s, so that Sweden subsequently regained its position as the Scandinavian country with the lowest first-birth fertility at the younger ages.

In a similar fashion, Figure 3 contains the standardized first-birth rates for childless women at ages 30-44. At these ages, both the trends over time and the levels of birth intensities are practically identical for women in Norway and Sweden, with no change at all during 1971-1984, followed by a pronounced increase in birth intensities during the second half of the 1980s, and less clear-cut trends during the 1990s. The sharp increase during the 1980s reflects the tendency of a general postponement of entry into motherhood in these countries; as it follows the previous decline at the younger ages (Figure 2). Levels and trends in first-birth fertility of the "older" women in Denmark are very similar to those of the corresponding women in Norway and Sweden. The main difference is that the turnaround to increasing fertility in Denmark occurred a few years later than in the other two countries. As a result, during the 1980s first-birth fertility of women aged 30-44 in Denmark was around 10-15 percent lower than that of corresponding women in Norway and Sweden. However, in Denmark, the increase in first-birth fertility of women in this age group proceeded well through the mid-1990s, so that by then the levels of corresponding fertility were once again the same in the three countries considered.

By contrast, trends in standardized second-birth rates (Figure 4) are characterized by a greater variation between countries. This holds for the developments during the 1980s and the 1990s; during the 1970s, levels and trends were instead very similar. For Norway, second-birth rates have been fairly stable during the entire study period, with a moderately falling trend up to 1977 , and a subsequent stable or weak upward trend. In Denmark, second-birth rates decreased until the early 1980s and subsequently increased during 1984-1995, and then regained the levels of the early 1970s. For Sweden we observe a very steep increase in second-birth fertility during the 1980s, followed by a 
Demographic Research - Special Collection 3: Article 7

-- Contemporary Research on European Fertility: Perspectives and Developments --

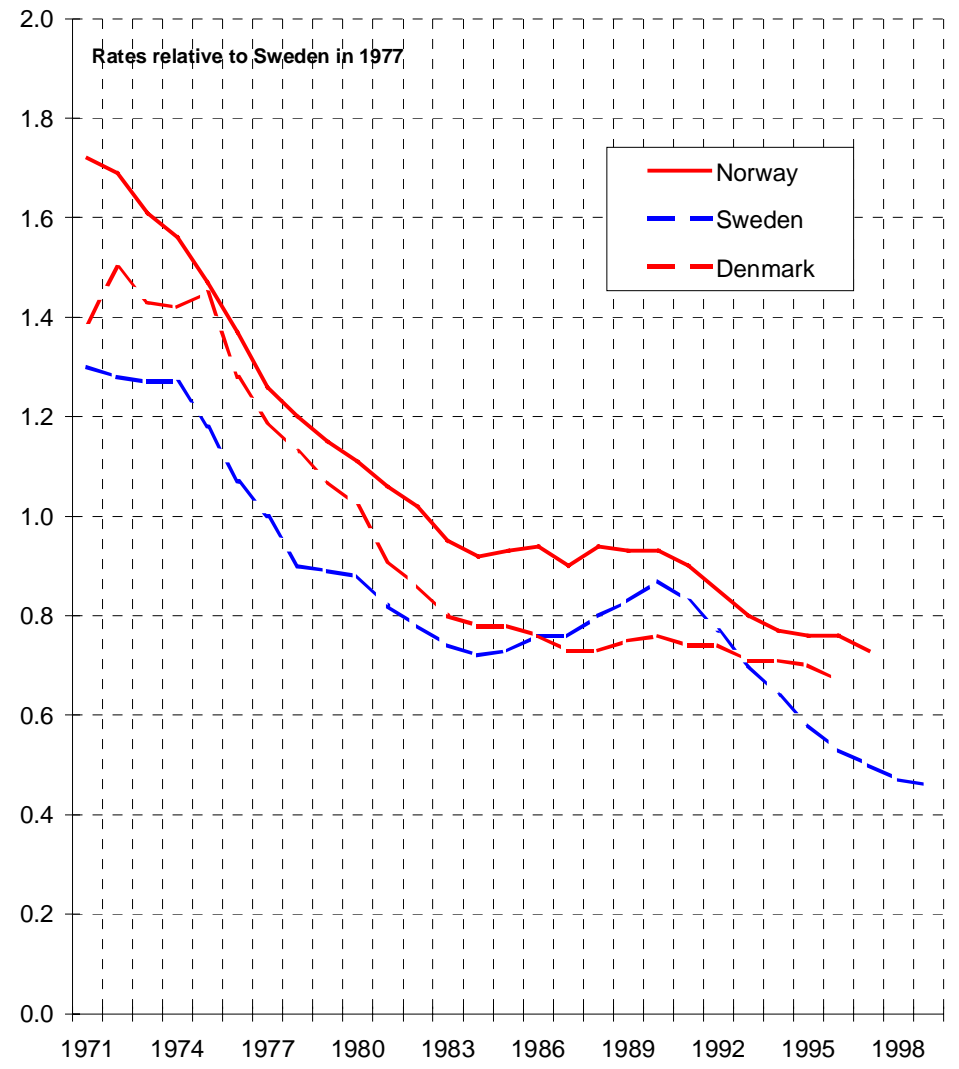

Figure 2: $\quad$ Standardized annual index of first-birth rates. Childless women in Denmark, Norway, and Sweden aged 15-29, 1971-1999. 
Demographic Research - Special Collection 3: Article 7

-- Contemporary Research on European Fertility: Perspectives and Developments --

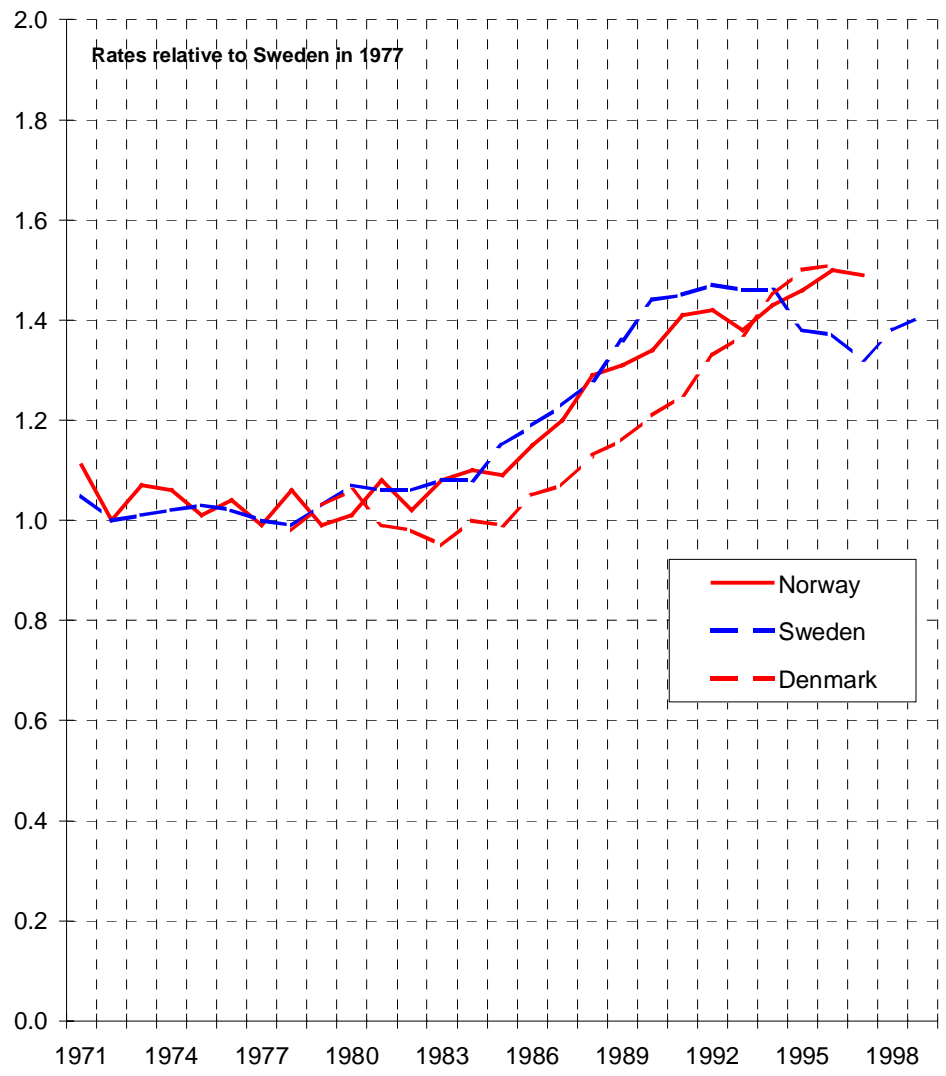

Figure 3: $\quad$ Standardized annual index of first-birth rates. Childless women in Denmark, Norway, and Sweden aged 30-44, 1971-1999. 
Demographic Research - Special Collection 3: Article 7

-- Contemporary Research on European Fertility: Perspectives and Developments --

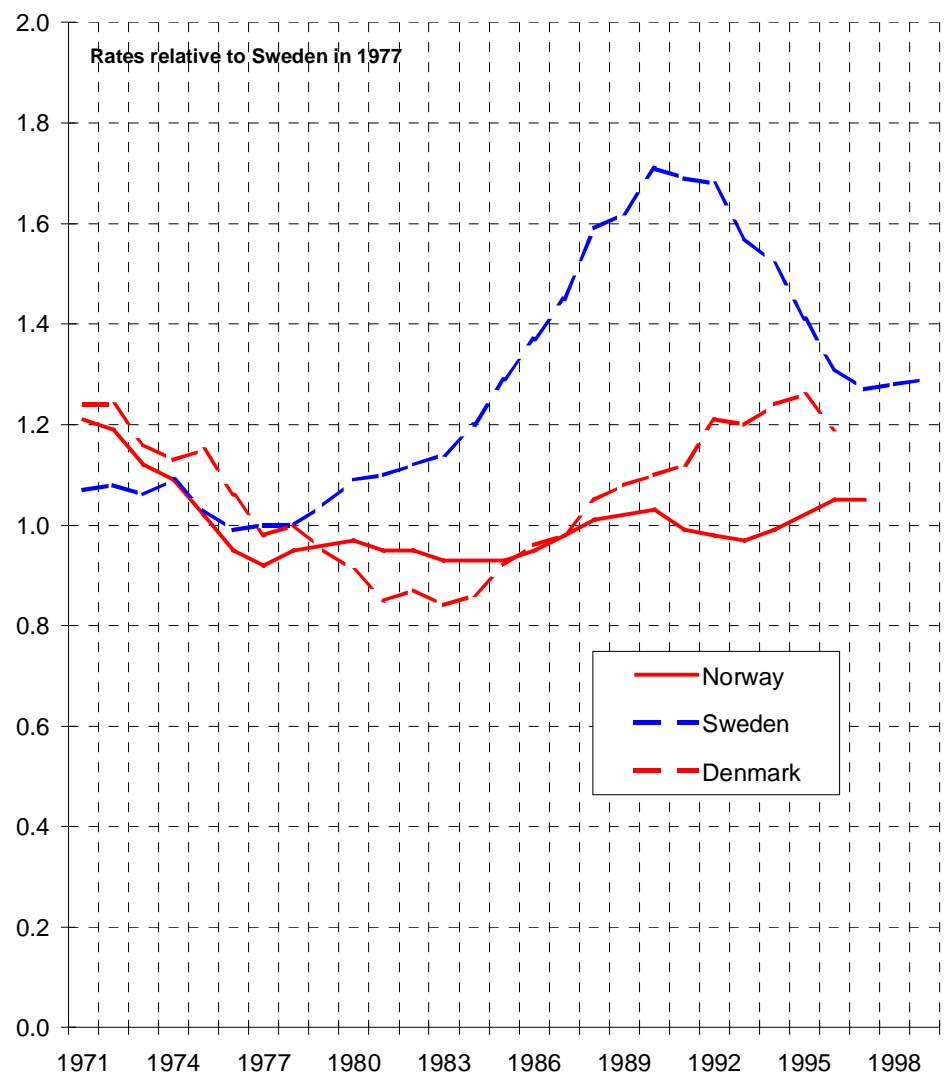

Figure 4: Annual index of second-birth rates. One-child mothers in Denmark, Norway, and Sweden, 1971-1999; standardized for age of mother and age of first child. 
Demographic Research - Special Collection 3: Article 7

-- Contemporary Research on European Fertility: Perspectives and Developments --

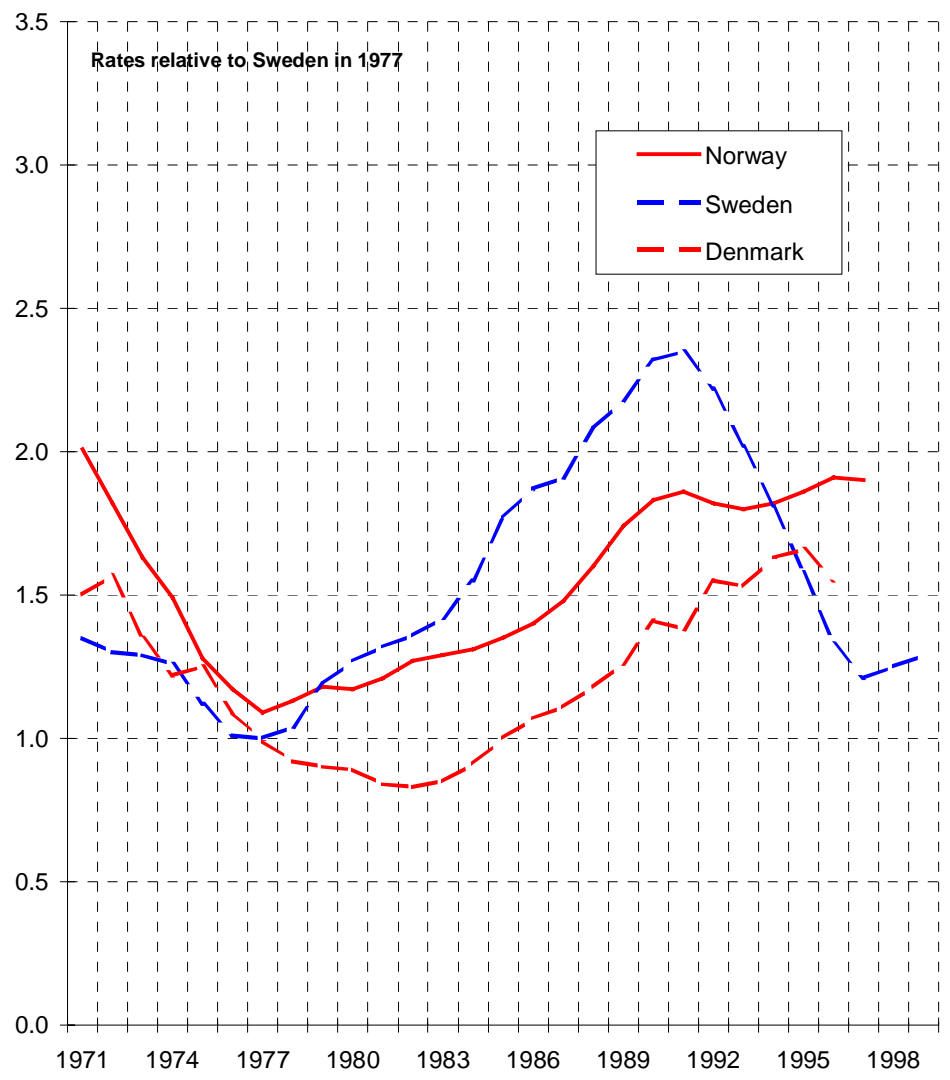

Figure 5: Annual index of third-birth rates. Two-child mothers in Denmark, Norway, and Sweden, 1971-1999; standardized for age of mother and age of second child. 
Demographic Research - Special Collection 3: Article 7

-- Contemporary Research on European Fertility: Perspectives and Developments --

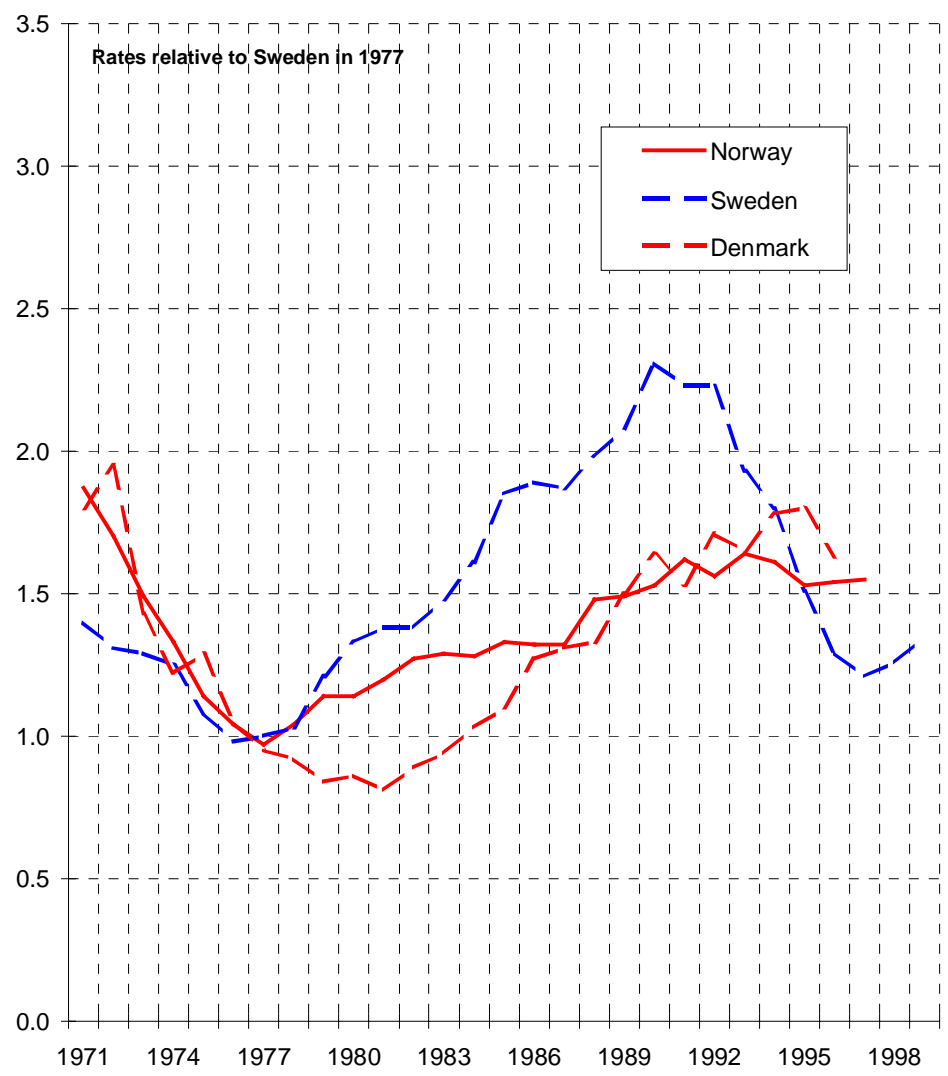

Figure 6: Annual index of fourth-birth rates. Three-child mothers in Denmark, Norway, and Sweden, 1971-1999; standardized for age of mother and age of third child. 
fallback in birth risks between 1992 and 1997. To a large extent, the increase in Swedish second-birth risks during the 1980s was related to a drastic change in the birthspacing behavior of parents in that country; continued childbearing begun to occur at a much faster tempo than during earlier decades (Hoem 1993b, Andersson 1999). We will return to an examination of such aspects when we compare and contrast the changes that have occurred (or have not occurred) in the birth-spacing behavior of mothers in the three Scandinavian countries.

In Figures 5 and 6, we complete our description of childbearing trends by giving standardized third- and fourth-birth rates, respectively, by period and country. At these higher birth orders, the relative changes in fertility levels over calendar years have been fairly swift. In each country, the developments of third- and fourth-birth risks are very similar to each other. During most of the 1970s, higher-order birth rates of mothers in the three countries declined in parallel to each other, and levels of birth risks were quite similar in the three countries. In Norway and Sweden, trends in third- and fourth-birth risks reversed in 1977. In Denmark, the decline continued for a few years, and the corresponding birth rates only display clear increases from 1983 and onwards. In Norway and Sweden, the increases of the 1980s were again interrupted in the early 1990s. In Sweden, trends reversed; in Norway they just leveled off. In Denmark the increases in higher-order childbearing proceeded well up to the mid-1990s. In general, developments have been far more volatile in Sweden than in its two neighboring countries. During the 1980s, third- and fourth-birth rates were markedly higher in Sweden than in Norway and Denmark. By the end of the study period such birth rates were, instead, lower in Sweden than in the other two countries. During most years, however, third-birth risks have been the lowest in Denmark.

\section{Fertility rates by age of mother and time since previous birth}

We conclude our comparison with an examination of patterns in childbearing by age of woman and any youngest child of hers. So far, we have used these variables mainly as control variables, but they can also give additional insights into various aspects of the childbearing behavior of women in the Scandinavian countries. Our presentation of first-birth rates revealed that trends in childbearing of younger and older childless women differ markedly from each other (Figures 2-3), and that first-birth rates of young Norwegians have been higher than the corresponding rates of young Danes and Swedes. For birth risks of mothers, by contrast, the period effects do not differ systematically by age (not shown). In addition, the basic patterns of second- and third-birth risks by age

of mother are fairly similar in the three countries (Figure 7a and 7b). One interesting 
Demographic Research - Special Collection 3: Article 7

-- Contemporary Research on European Fertility: Perspectives and Developments --

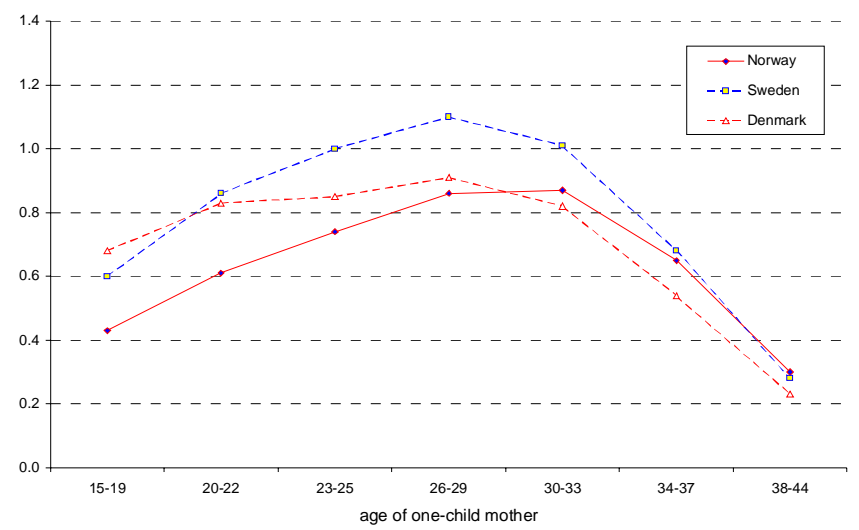

Figure 7a: Second-birth rates* by age of one-child mother, Denmark, Norway, and Sweden; standardized for calendar year and age of first child.

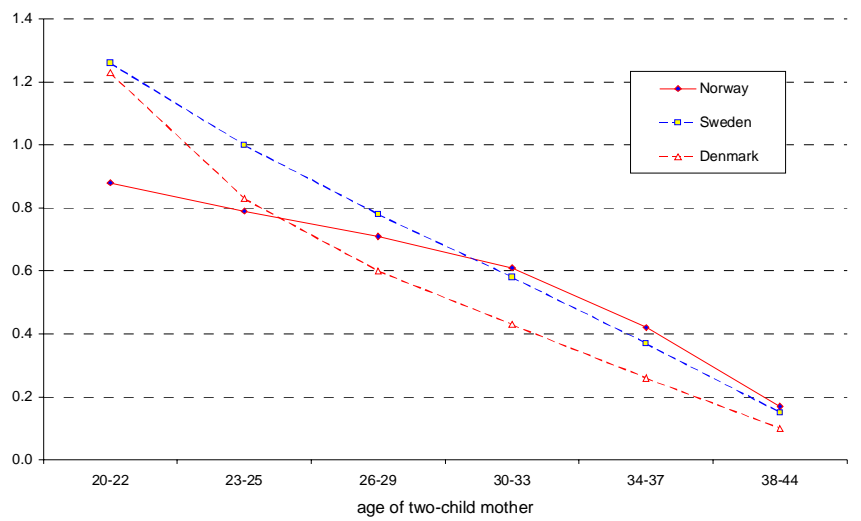

Figure 7b: Third-birth rates* by age of two-child mother, Denmark, Norway, and Sweden; standardized for calendar year and age of second child.

${ }^{*}$ Rates relative to that of a mother in Sweden aged 23-25 years 
feature, however, is that young Norwegian mothers, at ages 25 and below, appear to have slightly lower second- and third-birth risks than mothers at corresponding ages in Sweden and Denmark. This is exactly the opposite of the relationship by country for childless women at the younger age bracket (Figure 2), and might indicate that larger fractions of first births of young women in Norway are followed by some kind of "stopping behavior" in the childbearing process. Perhaps such a pattern, to a relatively large extent, is due to entry into motherhood of lone women, or to women becoming lone mothers shortly after the arrival of their first child? Skrede (2003) suggests that elevated levels of first-birth fertility of young women in Norway may be partly related to a special support scheme for lone mothers in that country.

In addition, we examine to what extent patterns in birth spacing have changed during our study period, in order to clarify how such changes might have been related to our observed general changes in the childbearing intensities of mothers in the three countries. We focus on second-birth risks by time since previous birth, since changes in such patterns are much clearer to display than corresponding changes in the heavily fluctuating higher-order birth risks. For this purpose, we present second-birth rates, by time since birth of any first child, in two selected years: 1980 and 1995. We have chosen these years since no important change in birth-spacing practices occurred prior to 1980 in any of the three countries considered (not shown), and since 1995 is one of the last years for which we have data. Figure 8 provides one diagram with rates of this kind for Denmark, Norway, and Sweden, respectively. (All risks are given relative to that of a mother with a youngest child aged 2 in Sweden in 1977.) A comparison of patterns and changes in patterns between countries is instructive. In Norway, secondbirth rates by age of the first child hardly changed at all during the study period. Norwegian mothers typically give birth to their second child more than three years after a first child is born, and this birth-spacing practice has been fairly permanent throughout our study period. In Denmark, the levels in second-birth risks increased substantially from 1980 to 1995 , but patterns in birth spacing remained stable. The birth-spacing pattern is similar to that of Sweden in 1980: Second-birth risks are more or less equally high at ages 2-4 years of the first child. Finally, for Sweden we demonstrate the change in birth-spacing practice that occurred in that country subsequent to 1980. Second-birth risks were considerably higher in 1995 than in 1980, but this only applies to childbearing at the shortest birth intervals. In Sweden, childbearing propensities now peak before the first child turns 3. Evidently, the net increase that can be observed in second-birth risks of Swedish mothers from 1980 to 1995 (Figure 4) is entirely due to elevated levels of childbearing at the short birth intervals, while the corresponding increase in Denmark stems from increasing birth propensities at all ages of any first child. 
Demographic Research - Special Collection 3: Article 7

-- Contemporary Research on European Fertility: Perspectives and Developments --
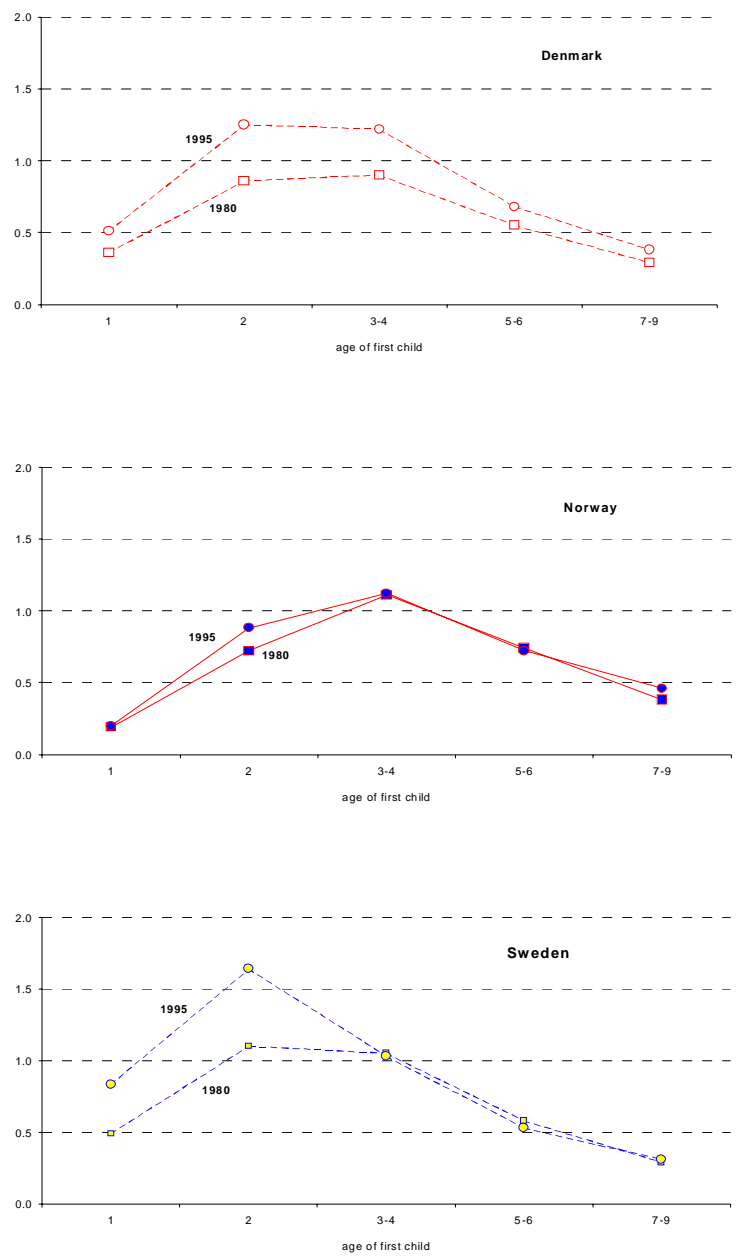

Figure 8: $\quad$ Second-birth rates by age of first child, Denmark, Norway, and Sweden in 1980 and in 1995; standardized for age of mother. (Rates relative to that of a mother with a child aged 2 years in Sweden in 1977.) 


\section{Reflections}

In the present study, we have provided an overview of recent trends in childbearing in the three Scandinavian countries: Denmark, Norway, and Sweden. By making efficient use of population-register data, we have been able to derive a very illuminating crosscountry comparison of the fertility developments in the three countries over the last three decades of the twentieth century. We discovered that, to some extent, trends have been relatively similar in the three countries, but that each country also has its own specific patterns. Trends in childbearing in Sweden have been much more volatile than corresponding trends in the two other countries. Trends in Denmark seem to lag somewhat behind the childbearing developments as they show up in Norway and Sweden.

To a large extent, developments in Norway and Sweden have indeed been very synchronized, even though the trends of Sweden have been far more volatile than those of Norway. Important turning points in fertility developments are noticeable for birth risk of mothers in 1977, for birth risks of childless women in the mid-1980s, and for birth risks at all birth orders in 1990-91. For Denmark, one very decisive turning point in childbearing developments occurred in 1983, while another one, marking a stabilization of fertility levels, seems to have appeared by the mid-1990s. These turning points for Denmark are common to women at all parities.

In Sweden, yet another trend reversal appeared in 1997. (For subsequent developments, see an update of Swedish trends by Andersson 2003). This reversal, like the one observed exactly twenty years earlier, does not show up in any description based on aggregated TFR values. We take this feature as an encouraging example of the advantages of our more refined method of analysis, which allows for the prompt detection of true changes in underlying behavior. Such changes can otherwise remain undiscovered, as they disappear in various simultaneous changes in the composition of women at childbearing ages. The country where, in retrospect, the TFR seems to be least problematic to use as a fertility indicator is Denmark, since fertility trends at the different birth orders have been so strongly synchronized in that country.

While Swedish fertility trends stand out with their roller-coaster pattern (Hoem and Hoem 1996), and Danish trends with their delayed development, we have found some other country-specific features in childbearing behavior as well. For Norway, we revealed a particular pattern of childbearing at the younger ages, which to some degree might have been reinforced by a special support scheme to lone mothers in that country. Skrede (2003) argued that the elevated levels of first-birth fertility of young women in Norway seem to be partly related to this support scheme. In addition, one can well argue that such a scheme could be related to a slower repartnering process of existing lone mothers. If this were the case, we would most likely find a reduced propensity for 
continued childbearing for the group of lone mothers, as in the instance we observe for Norwegian mothers at the younger age bracket.

For Sweden, we have managed to shed further light on the distinct change in birthspacing behavior that occurred in that country during the 1980s. Hoem (1993b) and Andersson (1999) have already demonstrated the change to a higher tempo of childbearing in Sweden, and have also revealed how it was related to the introduction of a "speed premium" on childbearing in the parental-leave system of Sweden (Note 4). Normally, it is very difficult to say much about the impact on demographic behavior of various macro variables such as a policy change of this kind. In this particular case, one could, for example, argue that the policy intervention perhaps just strengthened a trend that was nevertheless under way. In a country where women are well established in the labor market, it could well be that a pattern of work-associated accelerated childbearing (Ní Bhrolcháin 1986a,b) could arise in any case, and produce similar changes in birthspacing practices, as those observed for Sweden. With our cross-country comparison, we are in a much better position to assess the impact of the actual policy intervention. By using two neighboring countries as controls, we can argue conversely that such a change in behavior would not have occurred without the introduction of the "speed premium", and we are better able to assess the magnitude of that intervention's effect.

We consider it very valuable to have derived a detailed description of the childbearing developments in Denmark, in the same manner as these developments have already been presented for Norway and Sweden. This has allowed us to get an equally good overview of the childbearing developments in Denmark, as in the other two Scandinavian countries. In addition, it has added comparative strength to our fertility data: We have been able to single out a number of traits in childbearing behavior that are specific to one country, and do not appear in the other two. It has allowed us to get a clear picture of the impact of a certain policy intervention in Sweden, and to get an idea of the existence of another policy effect on childbearing behavior in Norway. To some extent, however, the inclusion of Denmark into our description has also added some further confusion to our general picture of childbearing developments in the Nordic countries. In some aspects, trends in Denmark display a pattern that is different from that of the other two Scandinavian countries, with turning points from decreasing to increasing fertility, and from increasing to stabilizing (/decreasing) fertility, that differ from those observed in Norway and Sweden. There is no immediate suggestion why fertility initially declined for a relatively longer period of time in Denmark than in Norway and Sweden. One possibility is that Denmark, as a less rural country with closer ties to continental Europe, was by then more aligned to developments elsewhere in Western Europe, like those of neighboring Germany. The turnaround itself to increasing fertility from 1983 onwards occurred in tandem with an improvement in the business cycle in Denmark, and the onset of a period of various 
policy measures aimed at the reconciliation of parental obligations and working life (Knudsen 2002).

Nevertheless, to conclude, we wish to stress the similarities that we find in the childbearing dynamics of the Scandinavian countries after all. Trends have changed somewhat later in Denmark than in the other two countries, and have been more volatile in Sweden than in Norway and Denmark, but the underlying long-term developments have been fairly similar. During the mid-1970s, fertility levels of women in the three countries were the same in most groups. At the end of our study period, the three countries were about to return to a situation with very similar fertility levels. At most birth orders, the fertility of women in Denmark by then seems to have stabilized at levels where the fertility of women in Norway leveled off already by the beginning of the 1990s. In Sweden, fertility is once again increasing (Andersson 2003), where at the beginning of the present century, fertility appears to be approaching the corresponding levels of women in its neighboring countries.

A final suggestion based on our study might be that patterns in childbearing in Norway and Denmark, at the end of the twentieth century, reflect the patterns of a possible underlying Nordic fertility regime of that time. The fertility levels of such a regime can perhaps be used as a benchmark when making forecasts about the fertility that is likely to appear when a society orients itself towards the reconciliation of the active labor-force participation of women and men to the activities and responsibilities of childrearing (Note 5).

\section{Acknowledgments}

I am grateful to Øystein Kravdal for having aggregated the Norwegian data used in this study, in a manner that could be reconciled with my own aggregations of Danish and Swedish data, and for sharing his data set with me. In addition, I am grateful to the Statistical Centralbureau of the three countries, Statistics Denmark, Statistics Norway, and Statistics Sweden, for having organized the raw data that we used for our aggregations. 
Demographic Research - Special Collection 3: Article 7

-- Contemporary Research on European Fertility: Perspectives and Developments --

\section{Notes}

1. The data for Sweden are restricted to childbearing histories of Swedish-born women, and the data for Denmark are treated correspondingly. For Sweden, Andersson (2004) demonstrates that the childbearing behavior of foreign-born women deviates from that of the Swedish-born in that their childbearing propensities are typically elevated immediately after immigration, for example. Nevertheless, the period trends in the childbearing risks of foreign-born women bare close resemblance to those of their Swedish-born counterparts. By contrast, our Norwegian data also include the childbearing histories of foreign-born women living in Norway. This difference in data layout should not cause too many problems since the immigrant population of Norway is much smaller than that of Sweden.

2. We refer to our estimation method as "indirect standardization" because the maximum likelihood solutions for the parameters of an intensity-regression (proportional-hazards) model have the same structure as the improved form of indirect standardization that we use, as shown by Hoem (1993a).

3. We chose 1977 as our baseline year since it represents an important turning point in the childbearing trends of Norway and Sweden. The choice of baseline has no effect on the patterns of the curves we present: It only sets the level of our risks, i.e. the scale of the y-axis of our diagrams.

4. The "speed premium" refers to rules that were introduced in the Swedish parentalleave system, and that allow parents (typically a woman) to keep an earlier (and often higher) level of income compensation during leave if a next child arrives within a fixed period of time. In 1980, this period was set to 24 months, and in 1986 it was extended to 30 months.

5. The recuperation of fertility levels that occurred in the Nordic countries during the 1980s is often considered related to the introduction of various packages of policies designed to facilitate a reconciliation of male and female employment to childrearing. For a further discussion of the role of such factors in creating pathways to highest-low fertility, see, for example, Bernhardt (1993), Brewster and Rindfuss (2000), Ellingsæter and Rønsen (1996), B. Hoem (1993), Rindfuss and Brewster (1996), and Sundström and Stafford (1992). 


\section{References}

Andersson, G., 1999. "Childbearing trends in Sweden 1961-1997." European Journal of Population 15: 1-24.

Andersson, G., 2002. "Fertility developments in Norway and Sweden since the early 1960s." Demographic Research 6: 67-86. Available http://www.demographicresearch.org/Volumes/Vol6/4.

Andersson, G., 2003. "Demographic trends in Sweden: An update of childbearing and nuptiality through 2002.” MPIDR Working Paper 2003-034. Max Planck Institute for Demographic Research, Rostock.

Andersson, G., 2004. "Childbearing after migration: Fertility patterns of foreign-born women in Sweden." International Migration Review 38(1): forthcoming.

Bernhardt, E., 1993. "Fertility and employment." European Sociological Review 9: 2542.

Bongaarts, J., and Feeney, G., 1998. "On the quantum and tempo of fertility." Population and Development Review 24: 271-291.

Brewster, K., and Rindfuss, R., 2000. "Fertility and women's employment in industrialized countries." Annual Review of Sociology 26: 271-296.

Ellingsæter, A.L. and Rønsen, M., 1996. "The dual strategy: motherhood and the work contract in Scandinavia." European Journal of Population 12: 239-260.

Hajnal, J., 1947. "The analysis of birth statistics in the light of the recent international recovery of the birth rate." Population Studies 1: 137-164.

Hoem, B., 1993. "The compatibility of employment and childbearing in contemporary Sweden.” Acta Sociologica 36: 101-120.

Hoem, B., and Hoem, J.M., 1996. "Sweden's family policies and roller-coaster fertility." Jinko Mondai Kenkyu (Journal of Population Problems) 52: 1-22.

Hoem, J.M., 1991. "La standardisation indirecte améliorée et son application à la divortialité en Suède (1971-1989)." Population 46: 1551-1568.

Hoem, J.M., 1993a. "Classical demographic methods of analysis and modern eventhistory techniques." IUSSP: 22nd International Population Conference, Montreal, Canada, Volume 3: 281-291.

Hoem, J.M., 1993b. "Public policy as the fuel of fertility: effects of a policy reform on the pace of childbearing in Sweden in the 1980s." Acta Sociologica 36: 19-31. 
Knudsen, L., 1993. "Fertility trends in Denmark in the 1980s." Statistiske Undersøgelser nr. 44. Statistics Denmark.

Knudsen, L., 2002. "An overview of recent fertility trends and family policies in Denmark". In: Carling, J. (ed.), Nordic Demography: Trends and Differentials. Nordic Demographic Society and Unipub, Oslo: 131-156.

Kohler, H.-P., and Ortega, J.A., 2002a. "Tempo-adjusted period parity progression measures, fertility postponement and completed cohort fertility. " Demographic Research 6: 91-144. Available http://www.demographicresearch.org/Volumes/Vol6/6.

Kohler, H.-P., and Ortega, J.A., 2002b. "Tempo-adjusted period parity progression measures: Assessing the implications of delayed childbearing for cohort fertility in Sweden, the Netherlands and Spain. " Demographic Research 6: 145-190. Available http://www.demographic-research.org/Volumes/Vol6/7.

Kravdal, Ø., 2002a. "The impact of individual and aggregate unemployment on fertility in Norway." Demographic Research 6: 263-293. Available http://www.demographic-research.org/Volumes/Vol6/10.

Kravdal, Ø., 2002b. "Is the previously reported increase in second- and higher-order birth rates in Norway and Sweden from the mid-1970s real or a result of inadequate estimation methods?" Demographic Research 6: 241-262. Available http://www.demographic-research.org/Volumes/Vol6/9.

Ní Bhrolcháin, M., 1986a. "Women's paid work and the timing of births." European Journal of Population 2: 43-70.

Ní Bhrolcháin, M., 1986b. "The interpretation and role of work-associated accelerated childbearing in post-war Britain." European Journal of Population 2: 135-154.

Ní Bhrolcháin, M., 1992. "Period paramount? A critique of the cohort approach to fertility." Population and Development Review 18: 599-629.

Rallu, J.-L., and Toulemon, L., 1994. "Period fertility measures: the construction of different indices and their application to France, 1946-89." Population: An English Selection 6: 59-94.

Rindfuss, R. and Brewster, K., 1996. "Childrearing and fertility." Population and Development Review, A Supplement to Vol. 22: 258-289.

Skrede, K., 2003. "Opening the black box: Some preliminary findings on early transition to parenthood and the role of cohabiting unions in early family formation in Norway." Paper presented at the Workshop: Das vernachlässigte 
-- Contemporary Research on European Fertility: Perspectives and Developments --

Geschlecht in der Familieforschung: Analysen zum Heirats- und Geburtenverhalten von Männern in Deutschland. 27-28 February 2003, Max Planck Institute for Demographic Research, Rostock.

Sobotka, T., 2003. "Tempo-quantum and period-cohort interplay in fertility changes in Europe. Evidence from the Czech Republic, Italy, the Netherlands and Sweden." Demographic Research 8: 151-213. Available http://www.demographicresearch.org/Volumes/Vol8/6.

Sundström, M. and Stafford, F.P., 1992. "Female labour force participation, fertility and public policy in Sweden." European Journal of Population 8: 199-215.

Van Imhoff, E., 2001. "On the impossibility of inferring cohort fertility measures from period fertility measures." Demographic Research 5: 23-64. Available http://www.demographic-research.org/Volumes/Vol5/2. 